\title{
Memorias literarias de la difteria: Mark Twain, W.G. Sebald y el síndrome de Stendhal
}

\author{
Walter Ledermann
}

\section{Hospital Luis Calvo Mackenna. \\ Recibido: 11 de diciembre de 2012 \\ Correspondencia a: Walter Ledermann Dehnhard oncemayor@gmail.com}

\author{
Literature memories about diphtheria: Mark Twain, W.G. Sebald and \\ Stendhal syndrome
}

Memories of W.G. Sebald from the diphtheria he suffered as a child, gave rise to a discussion about the origin of classic clinical descriptions and the traps memory tends. Good examples of the latter are some experiences of Stendhal, who must also be distrusted given his hypersensitivity, which gave name to a psychosomatic syndrome. Mark Twain, a more practical man, brings us back to reality with a funny story about the terror the disease caused in the late nineteenth century. This leads us to remember isolation measures and topical treatments from the period immediately preceding the antitoxin. They included manual removal of the pseudo membranes, maneuver that led Marañón to misinterpret a painting by Goya on a scene of "Lazarillo de Tormes".

Key words: Diphtheria, symptoms, history, Mark Twain, W.G. Sebald.

Palabras clave: Difteria, síntomas, historia, Mark Twain, W.G. Sebald.

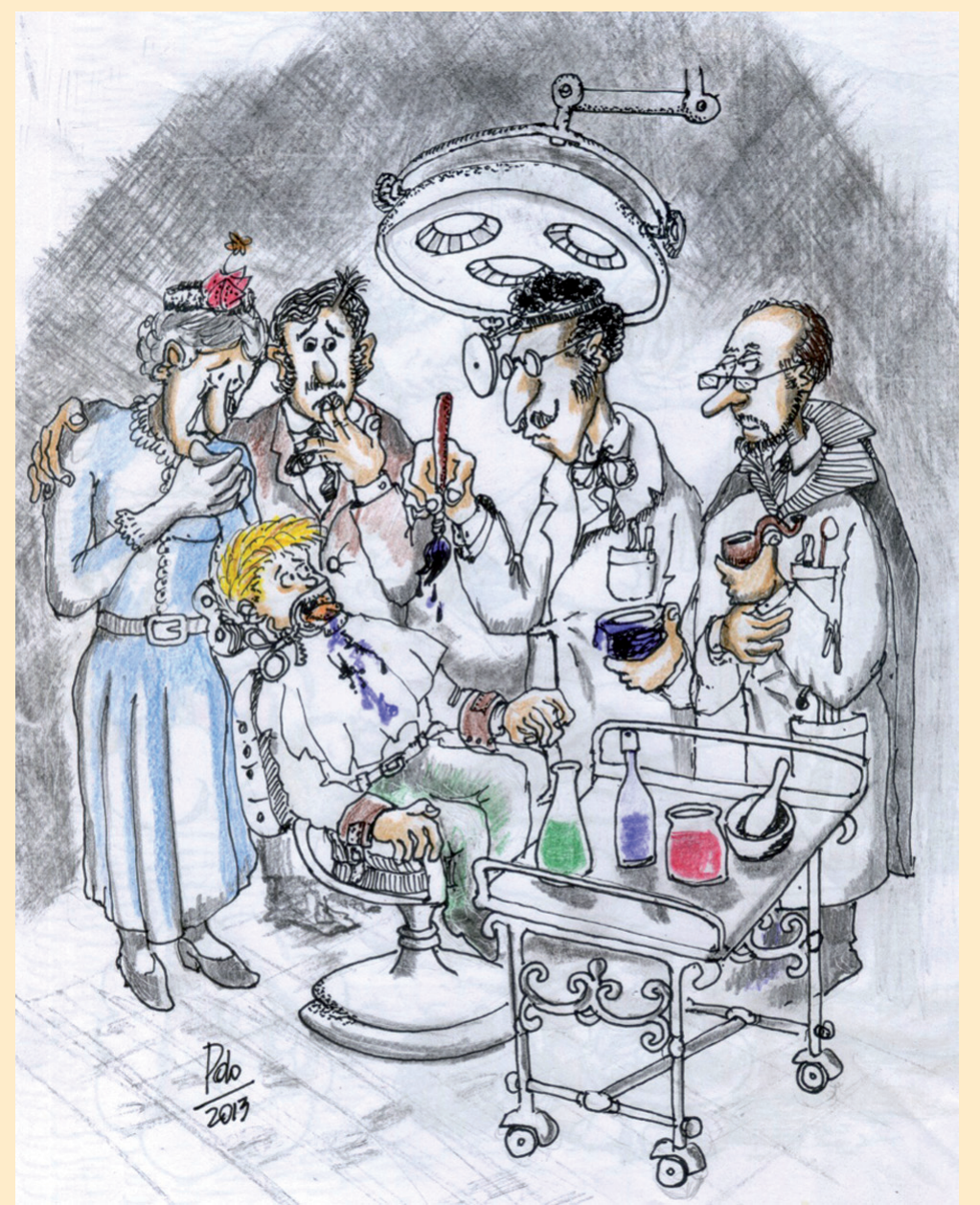

T a difteria, enfermedad prácticamente erradicada del mundo civilizado que utiliza el toxoide de Ramon, ha desaparecido de muchos programas de estudio de pediatría y de enfermedades infecciosas, al punto que al emprender una nueva edición de un texto educativo dudamos los editores si incluirla o no entre sus capítulos, preguntándonos cuántos médicos en ejercicio han visto alguna vez un caso de esta patología, qué conocimiento de ella tienen nuestros alumnos o cómo enfrentaríamos una epidemia en el caso, hipotético pero no improbable, que el profago beta mutara y una variante de la toxina hiciera inútiles antitoxina y vacuna.

Ociosa pregunta ésta, pues a diario la medicina, con sus vertiginosos avances, nos muestra que su evolución nos va dejando inevitablemente atrás, y apenas nos orientamos los médicos viejos entre las siglas de las polimerasas, los nuevos virus, los problemas nutricionales y los síndromes más raros, que van creando nuevas especialidades y subespecialidades, mientras el pasado, para nuestros jóvenes colegas, no existe.

¿Qué interés puede haber, entonces, en recordar las antiguas descripciones de una enfermedad en apariencia o realmente muerta? Sin embargo, quienes nos interesamos en la preservación de la memoria, seguimos revisándolas y preguntándonos si aquellos viejos maestros, como Bretonneau y Trousseau, que crearon los términos difteritis y difteria, describieron los síntomas que narraban sus pequeños pacientes y los signos que en ellos veían, o si, habiendo sufrido en su infancia la enfermedad, pusieron en sus monografías algún recuerdo personal.

Las epidemias de Tours, en Francia, que acopiaron material para estas descripciones, ocurrieron en 1821, 1825 y 1826 , cuando ambos maestros eran ya adultos y médicos formados, pero no es imposible que pequeños brotes anteriores hayan 
podido afectarlos. Sin embargo, si hubiesen de niños sufrido la difteria, nadie puede asegurar que sus recuerdos infantiles no se modificaran por las múltiples imágenes posteriores, presentes en los brotes epidémicos, llegando éstas a sustituirlos. En un intento para dilucidar esta duda hemos buscado apoyo fuera de la medicina, en la literatura, leyendo a Sebald.

Winfried Georg Sebald, escritor alemán del siglo XX, que firmaba sencillamente "W.G." dejó, antes de morir a los 56 años en un accidente automovilístico, un puñado de libros maravillosos e inclasificables, a medias entre el ensayo, la novela y la historia. En Il ritorno in patria ${ }^{1}$ nos entrega un relato de primera mano de los sufrimientos causados por la difteria, que procedemos a transcribir:

Con la faringe dolorida, más adelante lastimada y por último completamente abierta por dentro, yacia en mi cama mortificado cada pocos minutos por una fuerte tos, que me descomponía el pecho y el cuerpo entero... Mis miembros tenían una pesadez tal, para mí incomprensible, que no podía levantar la cabeza, las piernas o los brazos, ni siquiera las manos. En las cavidades de mi cuerpo había tanta presión como si mis órganos fuesen estirados por una prensa.

Aquí hacemos un alto y vamos a revisar qué hemos escrito nosotros en un libro y ¡oh, sorpresa!: nada de tos, nada de pesadez, nada de presión ${ }^{2}$. ¡Claro! De niños nunca tuvimos la enfermedad. Pero sigamos con Sebald: Varias veces me hizo estremecer la idea que el herrero sostenía mi corazón, recién sacado de la fragua incandescente, circundado por llamas azulinas como un cercado ardiendo, para introducirlo con unas tenazas de hierro en el agua gélida. Sólo el dolor de cabeza me llevaba a menudo al borde del desmayo ( $¡$ ay, no, tampoco la cefalea aparece en nuestro texto!), pero ya cuando en el punto máximo de la enfermedad la fiebre subia hasta quedarse apenas por debajo del límite decisivo, el delirio me liberaba de la más aguda sensación de dolor. Entonces me sentia envuelto en un calor vibrante, con los labios reventados, desfoliados, de color gris, y el sabor a podredumbre en la lengua a causa de la piel deteriorada de la faringe, como si estuviera en medio del desierto.

Bien: al fin encontramos algo clásico y reconocido, en este recuerdo de su cavidad oral sufriente. A continuación Sebald habla un poco de las medidas terapéuticas y de aislamiento, sin mencionar para nada la antitoxina, que ya se había utilizado en su país desde la navidad de 1891: El doctor Piazzolo, que al irrumpir la enfermedad había ordenado la transformación de mi dormitorio en un lazareto, al que sólo podían acceder mi abuelo y mi madre, me mandaba envolver de la cabeza hasta los pies en paños templados y húmedos, lo que al principio me sentaba muy bien, pero poco después me provocaba un miedo que se acrecentaba en mi interior cada vez más rápido. Mi madre tenía que lavar el suelo dos veces al día con agua de vinagre, y las ventanas de la habitación permanecian abiertas de par en par cuando menos durante el dia, por lo que a veces la nieve se introducía al interior hasta llegar casi a la mitad del cuarto...

En aquella época, al igual que en Chile, los hospitales eran para los pobres, y por ello en la clase media, a la cual Sebald pertenecía, hasta las enfermedades más severas se trataban en casa. El aislamiento descrito estaba bien, así como el acceso permitido a la madre y al abuelo, supuestamente ya inmunes a la difteria por haberla sufrido en la infancia, mientras que el vinagre como antiséptico provoca una sonrisa, y si las ventanas abiertas, seguramente para que el aire frío permitiera al niño respirar mejor, nos causan un escalofrío...¿cuántos le causarían al pobrecillo? La enfermedad - prosigue Sebald - duró más de dos semanas, hasta pasadas las navidades, y por fin el día de los Reyes Magos pude tomar unas cucharadas de pan y de leche. La puerta del lazareto se pudo abrir un poco, y en el umbral aparecieron por turnos algunos de los habitantes de la casa...

Sin embargo, en Beyle o el extraño hecho del amor, otra historia narrada antes en el mismo libro (pp. 9-13), el autor alemán nos había puesto en guardia contra los errores de la memoria, haciéndonos pensar cuántos de estos síntomas y de estos hechos eran recuerdos propios, y cuántos habían sido sugeridos por sus familiares al relatarle una y otra vez, en el curso de los años, los momentos de cruel incertidumbre vividos por todos en la casa. Cuenta Sebald que Stendhal, cuando era un joven de 17 años y aún se llamaba Beyle, participó del famoso cruce de los Alpes que hiciera el ejército de Napoleón con 36.000 hombres a mediados de mayo de 1800; y que más tarde, ya de 53 años, escribió unas notas intentando recordar sus vivencias de esta hazaña. En Martigny, relata Stendhal, vio al general Marmont vestido de azul real y azul celeste, como los consejeros de Estado; ahora, al momento de escribir, cerraba los ojos y aparecía así vívidamente en su recuerdo; no obstante, sabía con toda seguridad que en plena campaña no podía vestir de esta guisa y que debía haberlo hecho con su uniforme de general. A mayor abundamiento, da como ejemplo de las traiciones de la memoria el no poder recordar la maravillosa Madonna de San Sisto, vista por la misma época en Dresde, pues a esa imagen se le superponía de continuo el grabado que Müller había hecho de esta pintura. Así, pues, si al escribir el capítulo de coqueluche para algún manual de enseñanza, quisiéramos basar la descripción de sus síntomas en la dolorosa experiencia de haberla sufrido en la infancia, con seguridad nuestra memoria sería engañada, aceptando como propios y sufridos síntomas y signos que a lo largo de los años hemos visto, ya adultos, en el ejercicio de nuestra profesión.

Pero quizás no debiéramos prestar mucha atención a Beyle-Stendhal, pues era individuo hipersensible y dado a 
la exageración, como se acusa al relatar la impresión que le produjera una visita que hiciera en 1817 a la Basílica de la Santa Cruz en Florencia, tras la cual casi se desmaya: Había llegado a ese punto de emoción en que chocan las sensaciones celestes proporcionadas por las bellas artes con los sentimientos apasionados ...Al salir de la Santa Cruz me latía el corazón, la vida estaba agotada en mí, andaba temeroso de caerme... ${ }^{3}$.

No era el único exagerado: al parecer, Florencia "agotaba la vida" en muchos románticos, siendo frecuentes a través de todo el siglo XIX los desmayos causados por las bellas obras de la Galleria degli Uffizi, lo que ha llevado más tarde a la psiquiatra italiana Graziella Magherini a describir, tras observar un centenar de casos, "el síndrome de Stendhal", también llamado "de Florencia”. Según Graziella, se trataría de una entidad psicosomática, caracterizada por taquicardia, vértigo y confusión e incluso alucinaciones, desencadenado por la visión de obras de arte que rozan la sublimidad ${ }^{4}$. ¿Qué valor podemos dar, entonces, a sus recuerdos de su visita a la Maddona de San Sisto en Dresde, si casi se muere ante la Santa Croce? ¿Qué lucidez, qué validez pueden tener los recuerdos de un hombre cuya mente en el momento de los hechos estaba obnubilada por la belleza?

Mejor dejemos al sensible Stendhal y retrocedamos un poco en el tiempo en busca de un hombre más práctico y escéptico, que nos traiga de vuelta a la realidad. Mark Twain, escritor más longevo y prolífico que el alemán y que el francés, y que no solía meterse como éstos en análisis profundos, siendo todas sus obras -salvo las oscuras y ácidas El hombre que corrompió Hadleyburg y El forastero misterioso- de una agudeza, suave ironía e ingenio, que quitan el aliento sin causar ni por asomo un síndrome de Stendhal, escribió a fines del siglo XIX un gracioso relato sobre la difteria. Nos referimos a la historieta que lleva el largo título Lo que pasaron los Mcwilliamses cuando la epidemia de difteria, tal como se lo contó al autor de este libro el señor Mcwilliams, simpático caballero de Nueva York, con quien el susodicho autor se encontró casualmente durante un viaje.

Nada dice Twain de la sintomatología de la difteria, salvo, al igual que Sebald, una referencia a la tos, radicando la importancia del texto en que, bajo un disfraz humorista, retrata muy bien el pánico que causara la epidemia a fines de siglo. La gracia descansa en el continuo diálogo de la dominante señora Mcwilliams, cambiando perpetuamente de parecer, y su paciente marido, que sigue con total sometimiento sus órdenes. Se inicia con una discusión porque la niña Penélope está masticando un palito de pino, que el marido estima la madera menos nutritiva de todas cuantas un niño pequeño puede comer, a lo que la terca mujer opone la opinión de todos los médicos acerca de las bondades de la trementina de pino, buena para las espaldas y los riñones débiles.
La señora quita el palito a la niña, pues sabe que su marido tiene la razón y si lo contradice es sólo por hábito. La tragedia irrumpe más tarde, cuando ella con una cara tan blanca como una sábana, le comunica que hay otro caso de "garrotillo" en la vecindad. Este término pertenece a Amando Lázaro, el traductor español de la edición Aguilar que estamos consultando ${ }^{5}$, pues seguramente Twain ha escrito crup. "Garrotillo" deriva de "garrote", mecanismo de estrangulación con que en España se ajusticiaba en tiempos pasados, consistente en que al reo, de pie y apoyado en un poste, se le pasaba una cuerda alrededor del cuello, atando tras el poste ambos cabos a un palo (garrote) que iba reduciendo el radio de la cuerda a medida que se lo giraba, como se hace al aplicar un torniquete. Como los niños con difteria solían morir ahogados por las seudo membranas, el ingenio popular llamó así a la cruel enfermedad.

Entonces, cuando la niñera trae a Penélope para dar las buenas noches, la niña deja escapar una ligera tos y la madre cae hacia atrás como herida de muerte. Pero de inmediato se levanta y empieza a dar órdenes y contraórdenes, cambiando a la cuna y a la niñera de una pieza a otra, para proteger del contagio al niño menor, aún bebé, cuya respiración la espanta:

-- Este sueño suyo de ahora tiene algo que es distinto. Da la impresión de que... de que respira con toda regularidad. ¡Qué cosa más terrible!

Penélope, en su sueño, tose dos veces más. En ese terrible momento, el médico manda avisar que está enfermo, en cama, y no puede acudir.

-- Esto es cosa de la Providencia -sentencia la mujer.Esto ha sido ordenado de antemano. Ese hombre no estuvo enfermo hasta ahora. No lo estuvo jamás.

El médico ha enviado una amarga medicina que la niña debe tomar cada hora.

-- ¡Cómo si tuviéramos por delante un año entero para salvar a nuestra hija! -exclama la señora Mcwilliams, acortando la indicación a cada diez minutos, en la seguridad que la difteria es una enfermedad incurable y la niña morirá antes que llegue el nuevo día. Al mismo tiempo, hace al pobre marido encender y apagar la estufa varias veces, pues encuentra la habitación ora muy fría ora muy cálida; lo manda a buscar grasa de ganso y untarle a la enferma todo el cuerpo y también ponerle cataplasmas de linaza; lo obliga a quitar la cuna de una corriente de aire, ubicarla junto al fuego e ir por más leche. Cuando éste, agotado, se duerme, la esposa lo despierta, furiosa y aterrada, diciéndole que la niña está sudando, lo cual para ella es muerte segura.

El marido parte a sacar al pobre doctor de su cama y lo arrastra a medianoche hasta la cuna de Penélope. El galeno dice que la niña no está muriendo, afirmación que la mujer toma como un insulto personal; que la tos obedece a alguna insignificante irritación de la garganta 
o cosa así; que haría a la niña toser más fuerte y que se desembarazase de aquella molestia. Le da una poción, la niña tiene un espasmo de tos y arroja una astillita de pino.

El marido toma venganza y dice al doctor que su señora puede informarle de los beneficios de la trementina del pino, en lo cual no andaba ella muy descaminada, pues era, justamente, uno de los tratamientos preconizados por entonces. Fueron, en efecto, los alemanes Bose, Taube, Satlow, Vogel y Siegel, quienes propusieron el uso "interno" de su aceite por "sus notables propiedades antisépticas”, según el sabio Herr Professor A. Eulenburg, especificando que debe darse una cucharadita de café dos veces al día a niños de hasta 5 años, y una cucharada mayor, de 15 gramos, a los niños de más edad; que Vogel lo prescribe al 1 por 10 en emulsión introducida cada dos horas por la nariz; y que Siegel lo ha usado en 47 casos, con preferencia a cualquier otra cosa, puro o mezclado con Málaga (?) o yema de huevo azucarada y unas gotas de coñac ${ }^{6}$. Seguramente era de trementina la infusión que el enfermo médico indicó tomar cada hora a la pequeña Penélope, quien parecía experimentar cierto alivio al beberlo.

Más útiles que los tratamientos "internos" parecen haber sido los "tópicos", soluciones harto tóxicas que se utilizaban para eliminar las pseudo membranas y erradicar al agente causal, ya plenamente identificado. En la edición de 1906 del texto de Comby ${ }^{7}$, bellamente escrito y ampliamente consultado por los pediatras chilenos de fines del siglo XIX y principios del XX, cuando se seguía a los maestros franceses y alemanes, reemplazado ahora que se sigue a los norteamericanos por el monótono e impersonal Nelson, se describe una serie de pinceladas amigdalinas con sustancias terribles: ácido fénico, cloral ácido cítrico, naftol, alcohol mentolado, papaína y clorato de potasa. Pero lo mejor, concluía Comby, era utilizar el stéresol, cuya fórmula reproducimos para algún caso de urgencia:

\section{Stéresol según Comby}

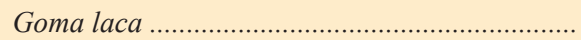

Benjuí......

Tintura de tolú.

Esencia de canela de China

Ácido fénico......

Alcohol $90^{\circ}$ q.s

Pincelar 2 a 3 veces al día

Estas pinceladas se combinaban con el uso de algunos "tónicos", como el coñac y el extracto de quinquina. Pero luego Comby borra de una plumada todo esto al hablar de la nueva maravilla, el suero antidiftérico de Roux (¡claro, como buen francés le quita la autoría a Behring y se la otorga a su compatriota!). Dice en su favor que en los años 1892 a 1894 el Anuario de la Ciudad de Paris registraba $1.557,1.216$ y 1.176 fallecidos de difteria, contra 435 en 1895 , luego de iniciarse la terapia con el suero.

Llama la atención cómo en la época del relato de Mark Twain no se usara el suero en Estados Unidos; o quizás el autor no lo conocía o escribió antes de 1890. En todo caso, es comprensible el pánico que sufriera la señora Mcwilliams, pues en la gran epidemia de los años 1880 la letalidad llegó al 50\% en algunas zonas del país. Y si todavía en 1921, según datos bien fiables del CDC, la letalidad era de $7,5 \%$, al fallecer 15.250 de los 206.000 enfermos, en tiempos del cuento de Twain los números deben haber sido escalofriantes. En cuanto al caso de Sebald, recordemos que durante la segunda guerra mundial hubo una epidemia en Europa, el año 1943, que afectó a un millón de personas y mató a cincuenta mil ${ }^{8}$.

La pugna entre el tratamiento local y la antitoxina nos lleva a la pintura, otra de las bellas artes. Entre 1802 y 1812 se supone que Francisco de Goya (1746-1828) pintó el cuadro conocido como El garrotillo, en que se ve a un hombre, tan andrajoso que no puede -o quizás sí- ser médico, bajando con dos dedos la lengua de un niño inmovilizado entre sus muslos. ¿Para mirar su garganta o para pincelar su faringe con algún tóxico ?... Nada de eso: el niño no tiene difteria y todo es un infundio del célebre médico español Gregorio Marañón, quien rebautizara así la pintura, pues esa fue la imagen que le trajo a su mente médica. En realidad, Goya pintó una situación de "El lazarillo de Tormes", cuando al protagonista le revisan la boca para ver si ha robado -y comido- unas longanizas. A Marañón, dueño del cuadro, le pareció que retrataba muy bien la desesperada maniobra popular de extraer manualmente las pseudo membranas para evitar la asfixia del paciente, y de ahí que en su pinacoteca la rebautizara como "El garrotillo". Actualmente la pintura estaría en manos de de doña Carmen Marañón, viuda de Araoz, en Madrid 9 .

A favor de la antitoxina y glorificando a Roux, existe una sosa pintura del francés Charles Maurin (1856-1914), cuyos tonos deslavados y sus imágenes idealizadas la hacen contrastar violentamente con la recia obra del español. La sérothérapie fue pintada en 1895, un año después que Roux llegara a su antitoxina, y se conserva en el Musée des Hospices Civils de Lyon. Roux constituye su figura central; de pie tras él están sus ayudantes Yersin y Martin; a un costado aparece un caballo, fiel amigo del hombre y donante del suero; por todas partes hay mujeres con sus hijos curados de la difteria; hay un fondo difuminado de casas y palacios. El diseño preparatorio de la obra se conserva, cual joya invaluable, en el Museo de Arte de Filadelfia, junto a una cursi poesía de Jean Richepin: 
Sonrisas de infantes curados, llamas de fiesta en los ojos maternales que no están ya llenos de lágrimas, cantos de todas nuestras aves salvadas de los cazadores, sean los diamantes, los laureles y las flores,

de los cuales se haga su corona ${ }^{10}$.

Si la pintura de Goya impresiona, ésta arranca una sonrisa piadosa, pero ni la una ni la otra causan, ni remotamente, un síndrome de Stendhal. Y si el lector no ha encontrado relación alguna entre éste y la difteria, le sugerimos releer cuidadosamente el texto dentro de unos diez años, cuando haya sentido el paso, leve pero destructor, del tiempo.

\section{Resumen}

A partir de los recuerdos de W.G. Sebald de la difteria que sufriera en su infancia, nace una discusión tanto sobre el origen de las clásicas descripciones clínicas como de las trampas que nos tiende la memoria, utilizando como ejemplo algunas vivencias de Stendhal, de quien también debemos desconfiar, dada su hipersensibilidad, que ha dado nombre a un síndrome psicosomático. Hombre más práctico, Mark Twain nos vuelve a la realidad con un gracioso relato sobre el terror que provocaba esta enfermedad a fines del siglo XIX, llevándonos a recordar las medidas de aislamiento y los tratamientos tópicos en la época inmediatamente anterior a la antitoxina, entre ellos la extracción manual de las pseudo membranas, maniobra que llevara a Marañón a interpretar erróneamente una pintura de Goya sobre una escena de "El lazarillo de Tormes".

\section{Referencias bibliográfícas}

1.- Sebald, G.W. Vértigo. Editorial Anagrama, Barcelona 2010; pp. 217-8.

2.- Ledermann W. Difteria. En: Banfi A., Ledermann W., Cofré J., Cohen J. y Santolaya, M.E. Enfermedades Infecciosas en Pediatría. $3^{\mathrm{a}}$. edición. Editorial Mediterráneo Ltda., Santiago 2004; pp. 351-4.

3.- Stendhal. Roma, Nápoles y Florencia. Editorial Pre-Textos. Madrid 1999.

4.- Magherini, G. El síndrome de Stendhal. Espasa Calpe, Madrid 1990.

5.- Twain, M. Novelas completas y ensayos. Aguilar S.A. de Ediciones, Madrid 1957; II : 1424-9.

6.- Eulenburg A. Diccionario Enciclopédico de Medicina y Cirugía Prácticas. Traducido directamente y arreglado para uso de médicos españoles por el Dr. Isidoro de Miguel y Viguri. Agustín Jubera, Editor, Madrid 1886; IV: 27.

7.- Comby, J. Traité des maladies de l'enfance. 5ème ed. Revue et considérablement augmentée. J. Rueff, éditeur. Paris 1906; pp. 15-39.

8.- WHO. Diphtheria Vaccine. Position Paper. Weekly epidemiological record 2006; 3: 24-32.

9.- Carmichel, A.G and Ratzan, R. M. Medicine in literature and art. Könemann, Koln 1991; p. 214.

10.- Farmitalia Carlo Erba. Il fármaco nei tempi. Dal laboratorio all'industria. Edizione italiana fuori commercio. Parma 1989; II: 98-100. 